\title{
Epidemiological characteristics and trends in the incidence of animal bites in Maku County, Islamic Republic of Iran, 2003-2012
}

Seyed Morteza Shamshirgaran 1,2, Hamid Barzkar ${ }^{1}$, Saber Ghaffari-Fam ${ }^{3}$, Ahmad Kosha ${ }^{4}$, Parvin Sarbakhsh ${ }^{1}$ and Pari Ghasemzadeh ${ }^{5}$

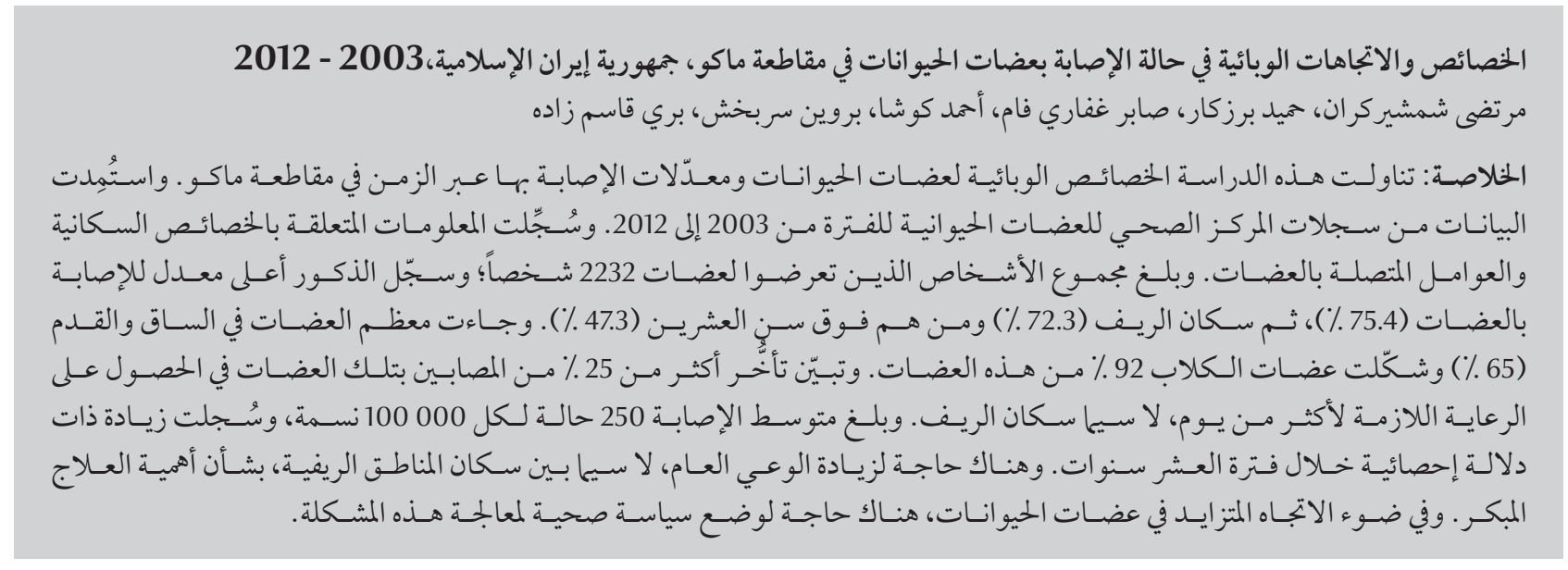

ABSTRACT This study examined the epidemiological characteristics and incidence over time of animal bites in Maku County. Data were obtained from health centre records of animal bites from 2003 to 2012. Information on demographic characteristics and bite-related factors were recorded. A total of 2232 people were bitten; the frequency of bites was highest among males (75.4\%), rural residents (72.3\%) and those < 20 years $(47.3 \%)$. Most bites were to the legs and feet (65\%) and dogs were responsible for $92 \%$ of bites. Over $25 \%$ of those bitten delayed seeking care for more than a day, particularly rural residents. The mean incidence was 250 per 100000 population and there was a statistically significant increasing linear trend over the 10-year period. There is a need to raise public awareness, especially among rural residents, of the importance of early treatment. Given the increasing trend in animal bites, a health policy to tackle this problem is needed.

\section{Caractéristiques et tendances épidémiologiques de l'incidence des morsures d'animaux dans la préfecture de Makou (République islamique d'Iran), 2003-2012}

RÉSUMÉ La présente étude a examiné les caractéristiques et l'incidence épidémiologiques dans le temps des morsures d'animaux dans la préfecture de Makou. Les données ont été obtenues à partir des registres de centres de santé portant sur les morsures d'animaux entre 2003 et 2012. Des informations sur les caractéristiques démographiques et les facteurs associés aux morsures d'animaux ont été enregistrées. Un total de 2232 personnes avaient été mordues. La fréquence des morsures était plus élevée parmi les hommes $(75,4 \%)$, les habitants ruraux $(72,3 \%)$ et les individus de moins de 20 ans (47,3\%). La plupart des morsures se situaient au niveau des jambes et des pieds (65\%) et les chiens étaient responsables de $92 \%$ des morsures. Plus de $25 \%$ des personnes mordues mettaient plus d'une journée à recourir à des soins, en particulier les habitants ruraux. L'incidence moyenne était de 250 pour 100000 habitants, et on observait une tendance linéaire en hausse statistiquement significative sur la période de 10 ans. Il est nécessaire de sensibiliser le public, et particulièrement les habitants ruraux, à l'importance d'un traitement rapide. Eu égard à la tendance croissante des morsures d'animaux, une politique sanitaire pour s'attaquer à ce problème est requise.

${ }^{7}$ Department of Statistics and Epidemiology, ${ }^{2}$ Road Traffic Injury Research Centre, Tabriz University of Medical Sciences, Tabriz, Islamic Republic of Iran. ${ }^{3}$ School of Nursing of Miandoab, Urmia University of Medical Sciences, Urmia, Islamic Republic of Iran. ${ }^{4}$ Department of Health Education, School of Health Sciences Tabriz University of Medical Sciences, Tabriz, Islamic Republic of Iran. ${ }^{5}$ Maku Health Centre, Maku, West Azerbaijan, Islamic Republic of Iran. (Correspondence to: Morteza Shamshirgaran: m.shamshirgaran@hotmail.com).

Received: 24/11/15; accepted: 28/11/16 


\section{Introduction}

Animal bites are a major cause of morbidity and mortality around the world, and are among the most important public health problems in some countries, such as in southern and eastern Mediterranean countries as well as in Middle Eastern countries with approximately $2 \%$ of the population being bitten annually $(1,2)$.

Numerous animal species can cause bites, however, most bites are from dogs, snakes, cats and monkeys. For example, snake bites are more frequent in Africa and South-East Asia. Evidence shows that dogs account for $76-94 \%$ of animal bite injuries in low- and middle-income countries (3).

In the Middle East, dogs are the main cause of animal bites followed by cats, cattle, sheep, goats, camels, donkeys and wild animals (1). Animal bites are an important health concern because of the risk of secondary infections and also the possibility of contracting rabies. The populations most at risk include young children and men (4). Animal bites can have a significant health impact; this depends on many factors including the type, size and location of the bite, health of the animal, health of the person bitten, and the health care received by the person bitten. Surveillance of animalrelated injuries can help determine the extent and scope of animal bites in order to provide useful information for implementation and evaluation of public health prevention interventions (5).

Animal bites are public health concern in the Islamic Republic of Iran and the pattern and frequency vary in different areas (6-10). Golestan province in the north of the country has a high incidence of animal bites (11) and the highest rate of animal bites has, recently, been reported from Aq Qala, Golestan province - 1222 bites per 100000 persons (12). Additionally, some studies have shown a change in the pattern and frequency of animal bites in the past 10 years (12-14). Recent reports from different parts of the Islamic Republic of Iran have indicated that animal bites are increasing. For instance, a study conducted in Rafsanjan city among 1542 patients referred to a health centre for animal bites from 2003 to 2005 estimated the incidence of animal bites in the area to be 180, 195 and 241 per 100000 persons in 2003, 2004 and 2005 respectively (14).

Maku County is located in West Azerbaijan province, north-west of the Islamic Republic of Iran. It has a population of about 90000 and an area size of 5000 square kilometres. This study was conducted to investigate the epidemiology and the time trend of animal bites in this county between 2003 and 2012.

\section{Methods}

\section{Study design and population}

This was a cross-sectional study conducted among 15 health centres in Maku County which serve all of the population of the county.

According to the Iran Health Network, people who are bitten by an animal are referred to the local health centre. A form is completed by trained staff for all referral cases of animal bites in each health centre. Therefore, the data of animal bites were compiled by the trained staff working in the Maku health centres. The study population included all the people who were bitten by animals and were referred to the health centres of Maku in the 10-year period from 20 March 2003 to 20 March 2012.

\section{Data collection}

Data were collected from the medical records of animal bites at the health centres in the study period. The variables of interest were: 1) Demographic variables including age, sex, occupation and education of the victims, 2) Place variables including place of residence of the person bitten and place where the bite occurred; 3) Time patterns including hour, day and season of the bite; 4) Characteristics of the animals such as the type and species of the animal and whether it was alive 10 days after the bite; 5) Location characteristics of bites including injury site, size of the wound, lesion type (superficial or deep) and whether the bite was covered by a cloth or not; 6) Health care received after the bite, e.g. number of vaccinations, tetanus vaccine received or not, infusion of rabies serum received, delay in receiving medicine after the bite and previous history of animal bites.

\section{Data analysis}

The crude incidence rate was determined on the basis of the total number of people bitten. To calculate the crude incidence rate, the population of the county by age group was obtained from the health centres of Maku.

Descriptive statistics were used to summarize the data. Mean and standard deviation (SD) were determined to show distribution of the data. For categorical variables, frequency was used. Age was categorized into 6 age groups: < 10 years, $10-19,20-29,30-39,40-49$ and $\geq 50$ years. The chi-squared test was used to assess the association of categorical variables; if $20 \%$ of the expected frequencies were $\leq 5$, the Fisher exact test was used. To compare the mean age of victims according to sex and place of residence, the Mann-Whitney test was used because the data were not normally distributed.

The chi-squared test for linear trend was used to test whether there was a statistically significant time trend in the incidence of animal bites.

A $P$-value of less than 0.05 was considered statistically significant.

\section{Ethical considerations}

The study protocol was reviewed and approved by the institutional Ethics Committee of Tabriz University of Medical Sciences. 


\section{Results}

A total of 2232 victims of animal bites were included in this study from 2003 to 2012. The majority of the people bitten had only 1 bite from the animal (96.1\%). The mean age of the victims was 25.11 (SD 17.47) years, ranging from 6 months to 89 years. The highest percentage of animal bites occurred in the age group of $10-19$ years (28.7\%). The majority of cases were men (75.4\%). The mean age of the males was 24.11 (SD 16.56) years and of females was 28.17 (SD 19.72) years, which was a statistically significant difference (Mann-Whitney test, $P=0.002$ ). More than half of those bitten $(57.7 \%)$ were illiterate or had received primary school education and the majority (72.3\%) were from rural areas. About one-third of the people bitten (33\%) were students, $15 \%$ were self-employed and $15 \%$ were housewives (Table 1).

In the univariate analysis in all age groups, the number of people bitten from rural areas was significantly higher than from urban areas $(P<0.001)$. The difference in mean age of the people bitten \#by the area of residence was statistically significant; those from rural areas were younger than victims from urban areas [24.65 (SD 17.75) versus 26.30 (SD 16.71) years] (Mann-Whitney test, $P=0.001$ ). Furthermore, there was a statistically significant association between place of residence and education level and occupation $(P<0.001)$ (Table 1).
The majority of the bites (34.9\%) occurred between 12:00-18:00. Saturday and Sunday, the first two days of the week in the official calendar of the country, had the most reported bites $-16.1 \%$ and $15.7 \%$ respectively (data not shown in tables).

Dogs accounted for $92.8 \%$ of the bites, with cats $5.2 \%$ and others $2.0 \%$. The highest percentage of animal bites (29.2\%) occurred in the summer and the lowest in the autumn (19.5\%). Among all the victims, $72.6 \%$ were referred to the health centre on the same day of the bite and $5.2 \%$ were referred 3 or more days after the bite (Table 2). There was a statistically significant association between place of residence and the type of animal that inflicted the bite $(P<0.001)$. There was also

\begin{tabular}{|c|c|c|c|c|c|c|c|}
\hline \multirow[t]{2}{*}{ Characteristic } & \multicolumn{2}{|c|}{ Total } & \multicolumn{2}{|c|}{ Rural } & \multicolumn{2}{|c|}{ Urban } & \multirow[t]{2}{*}{$P$-value ${ }^{1}$} \\
\hline & No. & $\%$ & No. & $\%$ & No. & $\%$ & \\
\hline Age group (years) & & & & & & & $<0.001$ \\
\hline$<10$ & 416 & 18.6 & 324 & 20.1 & 92 & 14.9 & \\
\hline $10-19$ & 640 & 28.7 & 487 & 30.2 & 153 & 24.8 & \\
\hline $20-29$ & 441 & 19.8 & 270 & 16.7 & 171 & 27.7 & \\
\hline $30-39$ & 262 & 11.7 & 187 & 11.6 & 75 & 12.1 & \\
\hline $40-49$ & 191 & 8.6 & 140 & 8.7 & 51 & 8.3 & \\
\hline$\geq 50$ & 282 & 12.6 & 206 & 12.8 & 76 & 12.3 & \\
\hline Sex & & & & & & & $<0.001$ \\
\hline Male & 1683 & 75.4 & 1158 & 71.7 & 525 & 85.0 & \\
\hline Female & 549 & 24.6 & 456 & 28.3 & 93 & 15.0 & \\
\hline Education & & & & & & & $<0.001$ \\
\hline Illiterate & 578 & 25.9 & 474 & 29.4 & 104 & 16.9 & \\
\hline Primary school & 709 & 31.8 & 546 & 33.9 & 163 & 26.5 & \\
\hline Secondary school & 512 & 23.0 & 368 & 22.8 & 144 & 23.4 & \\
\hline High school and higher & 429 & 19.3 & 224 & 13.9 & 205 & 33.3 & \\
\hline Occupation & & & & & & & $<0.001$ \\
\hline Student & 739 & 33.1 & 571 & 35.4 & 168 & 27.2 & \\
\hline Not working + child & 282 & 12.6 & 217 & 13.5 & 65 & 10.5 & \\
\hline Farmer/sheep keeper & 210 & 9.4 & 187 & 11.6 & 23 & 3.7 & \\
\hline Paid employment & 249 & 11.2 & 115 & 7.1 & 134 & 21.7 & \\
\hline Self-employed & 338 & 15.2 & 201 & 12.5 & 137 & 22.2 & \\
\hline Housewife & 334 & 15.0 & 290 & 18.0 & 44 & 7.1 & \\
\hline Other & 78 & 3.5 & 31 & 1.9 & 47 & 7.6 & \\
\hline
\end{tabular}

${ }^{I}$ Chi-squared test.

Some data were missing for education and occupation. 


\begin{tabular}{|c|c|c|c|c|c|c|c|}
\hline \multirow[t]{2}{*}{ Characteristic } & \multicolumn{2}{|c|}{ Total } & \multicolumn{2}{|c|}{ Rural } & \multicolumn{2}{|c|}{ Urban } & \multirow[t]{2}{*}{$P$-value ${ }^{1}$} \\
\hline & No. & $\%$ & No. & $\%$ & No. & $\%$ & \\
\hline Animal type & & & & & & & $<0.001$ \\
\hline Dog & 2072 & 92.8 & 1558 & 96.5 & 514 & 83.2 & \\
\hline Cat & 125 & 5.6 & 41 & 2.6 & 84 & 13.6 & \\
\hline Other & 35 & 1.6 & 15 & 0.9 & 20 & 3.2 & \\
\hline Season & & & & & & & 0.41 \\
\hline Spring & 602 & 27.0 & 439 & 27.2 & 163 & 26.4 & \\
\hline Summer & 652 & 29.2 & 465 & 28.8 & 187 & 30.4 & \\
\hline Autumn & 435 & 19.5 & 305 & 18.9 & 130 & 21.0 & \\
\hline Winter & 543 & 24.3 & 405 & 25.1 & 138 & 22.3 & \\
\hline Injury site & & & & & & & 0.02 \\
\hline Head and neck & 67 & 3.1 & 50 & 3.2 & 17 & 2.8 & \\
\hline Pelvis, abdomen & 231 & 10.8 & 185 & 12.0 & 46 & 7.6 & \\
\hline Shoulder, upper limbs & 387 & 18.1 & 217 & 14.2 & 170 & 28.2 & \\
\hline Lower limbs & 1457 & 68.0 & 1087 & 70.6 & 370 & 61.4 & \\
\hline Post-exposure treatment delay & & & & & & & $<0.001$ \\
\hline Immediate & 1616 & 72.6 & 1141 & 70.9 & 475 & 77.0 & \\
\hline 1 day & 338 & 15.2 & 258 & 16.0 & 80 & 13.0 & \\
\hline 2 days & 154 & 6.9 & 115 & 7.2 & 39 & 6.3 & \\
\hline$\geq 3$ days & 118 & 5.2 & 95 & 5.9 & 23 & 3.7 & \\
\hline
\end{tabular}

${ }^{1}$ Chi-squared test.

Some data were missing for injury site and post-exposure treatment time.

a statistically significant difference in delay time according to place of residence $(P=0.02)$.

In addition, $93.1 \%$ of the animal bites were caused by a domestic animal and $94 \%$ of the animals were alive 10 days after the bite. Only $13.2 \%$ of the victims received serum therapy and 99.4\% received tetanus vaccine on the first visit. Few of the victims reported a previous history of animal bites (3\%). The rabies vaccination was given once for $4.7 \%$ of the victims, twice for $14.9 \%$ and three times for $77.2 \%$.

Superficial lesions were seen in $86.4 \%$ of the injuries. In $83.6 \%$ of the bites, the bite was on clothes. The depth and extent of the wound was low in $85.7 \%$ of the injuries. Most of the injuries were on the lower extremity (68\%), followed by shoulder and upper limbs (Table 1). There was a statistically significant association between wound location and the type of animal inflicting the bite and also place of residence $(P<0.001)$. There was no sex difference in wound location; both in males and females, the highest proportion of injuries was on the leg(s) (data not shown in tables).

Table 3 shows the frequency of animal bites over time based on place of residence (urban/rural). The average incidence rate over the 10 years was 250 per 100000 persons. The highest incidence of animal bites was 295 per 100000 persons in 2010 and the lowest was 208 per 100000 in 2005. The trend of incidence of animal bites fluctuated with time; it increased from 2005 to 2008 and decreased from 2011 to 2013. Overall, a significant increasing linear trend of animal bites was observed (chi-squared test for trend 7.21, $P=0.007$ ) (Figure 1).

\section{Discussion}

In the present study, the majority of the people bitten were men, which agrees with the results of some other studies conducted in the Islamic Republic of Iran: in Kerman $73.48 \%$ of people bitten were men (13), in Tabriz 84.68\% (15), in Ardabil 75\% (16), in Khuzestan $62 \%$ (17), in the East of the Islamic Republic of Iran 78.3\% (18), in Tehran $79.16 \%$ (19), in Illam province $68.3 \%$ (10), in the Shush County $77.6 \%(20)$, and in Islamabad-Gharb County $72.5 \%$ (21). The higher rate of animal bites in men may be due to their job and outdoor activities.

In our study, animal bites were more common in rural areas and among individuals with lower education levels, and in students, housewives and self-employed people. This is similar to findings of other studies in the Islamic Republic of Iran (12,13,17,22).

The majority of animal bites in our study were among people in the age group of 10-19 years in both genders, which is in line with many studies that have been conducted in the Islamic Republic of Iran $(16,20,21)$. This might 


\begin{tabular}{|c|c|c|c|c|c|}
\hline \multirow[t]{2}{*}{ Year } & \multicolumn{2}{|c|}{ Urban } & \multicolumn{2}{|c|}{ Rural } & \multirow{2}{*}{$\begin{array}{c}\text { Total } \\
\text { No. }\end{array}$} \\
\hline & No. & $\%$ & No. & $\%$ & \\
\hline 2003 & 84 & 38.5 & 134 & 61.5 & 218 \\
\hline 2004 & 82 & 32.4 & 171 & 67.6 & 253 \\
\hline 2005 & 74 & 27.6 & 194 & 72.4 & 268 \\
\hline 2006 & 56 & 24.2 & 175 & 75.8 & 231 \\
\hline 2007 & 70 & 26.3 & 196 & 73.7 & 266 \\
\hline 2008 & 57 & 25.6 & 166 & 74.4 & 223 \\
\hline 2009 & 33 & 18.4 & 146 & 81.6 & 179 \\
\hline 2010 & 64 & 30.9 & 143 & 69.1 & 207 \\
\hline 2011 & 32 & 17.2 & 154 & 82.8 & 186 \\
\hline 2012 & 66 & 32.8 & 135 & 67.2 & 201 \\
\hline Total & 618 & 27.7 & 1614 & 72.3 & 2232 \\
\hline
\end{tabular}

be because this age group spends more time in outdoor activities.

Most of the bites were inflicted by dogs. This is similar to the results of some other studies such as a study from Illam province where dogs accounted for $89.2 \%$ of the incidence of animal bites (10), in Northern Iran where dog bites were reported by $84.87 \%$ of the people bitten (23), in a study from Tehran where dogs were responsible for $65.9 \%$ of animal bites (19), in the East of the Islamic Republic of Iran where dogs caused $80.3 \%$ of animal bites (18), and in the north-west of the country where dogs were responsible for $72.4 \%$ of animal bites (15). An explanation for this finding might be the key role played by dogs in rural life and the closeness of human beings with dogs in such places. The vast majority of the animal bites were caused by a domestic animal (93.1\%). The lower frequency of animal bites from dogs in urban areas such as Tehran (19) also lends support to this hypothesis.

We found that the majority of bites were to the lower limbs. Numerous studies in the Islamic Republic of Iran have reported a high frequency of animal bite injuries to the lower limbs: $75.8 \%$ of injuries were to the leg in Kassiri (Islamabad-Gharb, Kermanshah province) (21), 81.4\% were to the feet in Kassiri (Shush, Khuzestan province) (20), $71.8 \%$ were also to feet in Sabouri Ghannad (Illam province) (10), $52.93 \%$ were to the lower limbs in Najafi (northern Islamic Republic of Iran Iran) (23), 53.8\% were also to the lower limbs in Eslamifar (Tehran) (19) and $70.89 \%$ were to the legs in Majidpour

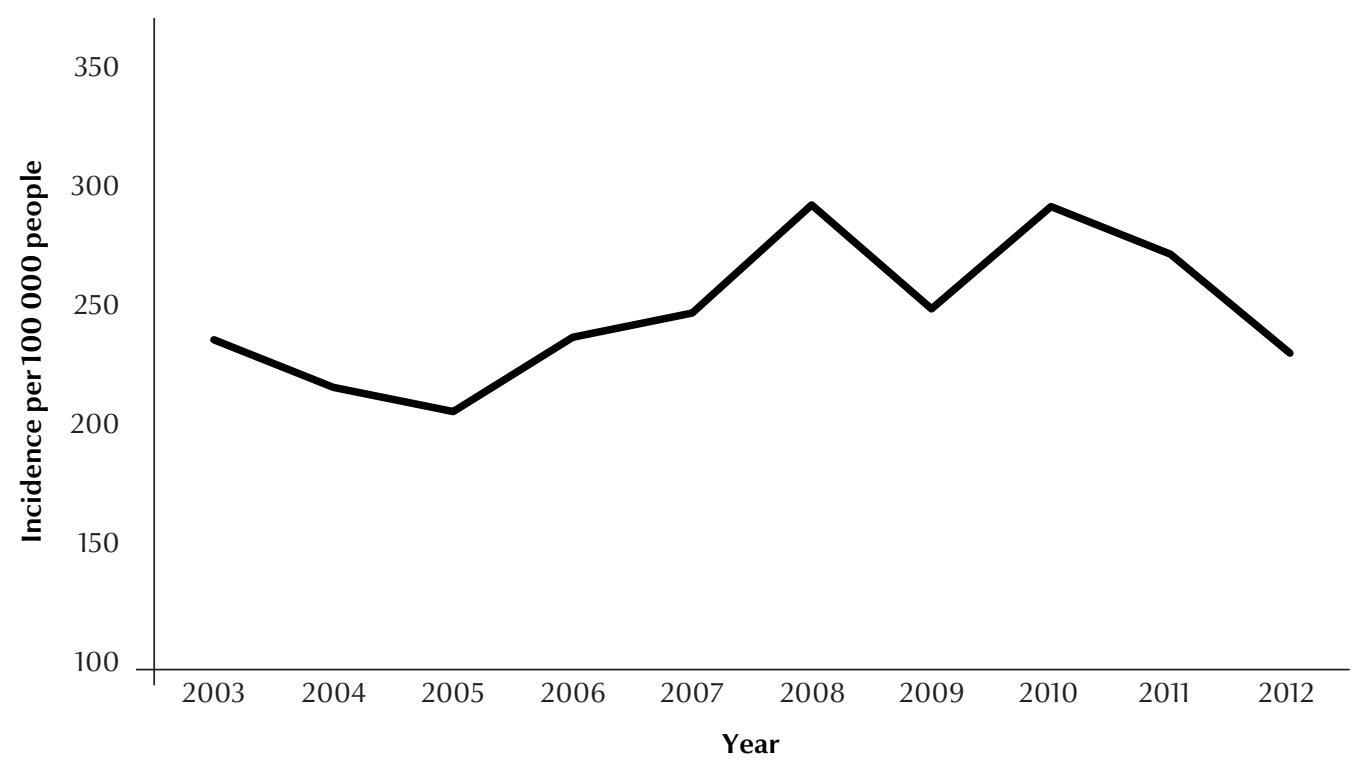

Figure 1 Trend in the incidence of animal bites, Maku County, Islamic Republic of Iran, 2003-2012 
(Ardabil) (16).This might be explained by the type of animal, i.e. dogs, as well as by the victim's body posture while being bitten by a dog and also by the fact that the lower limbs are an easy place for a dog to reach, especially for small dogs.

The highest proportions of the animal bites were in the summer and spring seasons, and on Saturdays and Sundays, which is in line with some studies in the Islamic Republic of Iran $(7,14)$. However, a study from a southern part of the country reported a higher frequency in autumn (20). This might be due to the longer day time and working hours spent on farms among people in rural areas in these regions.

Most of the people who were bitten in our study were referred for care immediately after the biting incident. However, over a quarter of them delayed seeking care for more than a day. There was an association between place of residence and delay in seeking care, with a greater delay among rural residents. A lack of frequent public transportation in the rural areas and a lack of knowledge about the dangers of animal bites might be the reasons for this difference.
The linear time trend in the incidence of animal bites was statistically significant. Overall, incidence rates of animal bites increased during the study period (2003-2012). Some studies in the Islamic Republic of Iran have also reported an increase in the incidence of animal bites in the past decades (14). This might be explained by an increase in awareness of people of the need to visit a health centre after a bite or it may reflect a true increase in animal bites. However, the incidence of animal bites decreased in the last 2 years examined in our study, so further study of more recent years is needed.

A limitation of our study is that the data were taken from medical records of the people who were bitten. It is probable that there were bite victims who did not seek care, especially those with minor injuries, and no registered data were available for them. Our finding may therefore be an underestimate of the incidence of animal bites in Maku.

\section{Conclusion}

Based on the results of our study, there was a delay in the treatment received by the people bitten, which indicates a need to raise awareness of the public, especially those who live in rural areas, of the health risks of animal bites and the importance of early treatment. Furthermore, bites by domestic dogs to the lower limbs are an important problem which should be tackled. The significant increasing linear trend of animal bites points to the need for a comprehensive health policy to prevent and control this problem. Surveillance of animal bites in different areas is recommended so as to gather evidence to implement prevention strategies.

\section{Acknowledgements}

The authors gratefully thank the personnel of the Maku health centres for their kind cooperation and the Epidemiology and Traffic Injury Prevention Research Centre of Tabriz University of Medical Sciences for their financial support.

Funding: This study was funded by the Epidemiology and Traffic Injury Prevention Research Centre of Tabriz University of Medical Sciences.

Competing interests: None declared.

\section{References}

1. Seimenis A. The rabies situation in the Middle East. Dev Biol (Basel). 2008;131:43-53.

2. Wunner WH, Briggs DJ. Rabies in the 21 century. PLoS Negl Trop Dis. 2010;4(3):e591.

3. World Health Organization. Animal bites. Fact sheet no. 373, February 2013 http://www.who.int/mediacentre/factsheets/ fs373/en/, accessed 20 March 2017).

4. Dendle C, Looke D. Review article: Animal bites: an update for management with a focus on infections. Emerg Med Australas. 2008;20(6):458-67.

5. Emet M, Beyhun NE, Kosan Z, Aslan S, Uzkeser M, Cakir ZG. Animal-related injuries: epidemiological and meteorological features. Ann Agric Environ Med. 2009;16(1):87-92.

6. Moini M, Peyvandi AA, Rasouli MR, Khajei A, Kakavand M, Eghbal $P$, et al. Pattern of animal-related injuries in Iran. Acta Med Iran. 2011;49(3):163-8.

7. Ghaffari-Fam S, Hosseini SR, Daemi A, Heydari H, Malekzade $\mathrm{R}$, Ayubi E, et al. Epidemiological patterns of animal bites in the Babol County, North of Iran. J Acute Dis. 2016;5(2):126-30.

8. Khazaei S, Ayubi E, Nematollahi S, Mansouri K, AhmadiPishkuhi M, Mohammadian-Hafshejani A, et al. Pattern of pediatric animal bites and post exposure prophylaxis in Isfahan Province-Iran, 2015. Int J Ped. 2016;4(6):1977-82.

9. Ansari-Moghaddam A, Martiniuk AL, Mohammadi M, Rad M, Sargazi F, Sheykhzadeh K, et al. The pattern of injury and poisoning in South East Iran. BMC Int Health Hum Rights. 2012;12:17.

10. Ghannad MS, Roshanaei G, Alikhani MY, Alijani P, Sardari MG. Animal bites in Borujerd: an overview of animal bites in Iran. Avicenna J Clin Microbiol Infect. 2014;1(1):e19568.

11. Zeinali A, Tajik P, Rad M. [Wild life diseases]. Donyaye andisheh. 2002;4:53 [In Farsi].

12. Charkazi A, Behnampour N, Fathi M, Esmaeili A, Shahnazi $H$, Heshmati H. Epidemiology of animal bite in Aq Qala city, northen of Iran. J Educ Health Promot. 2013;2:13.

13. Rezaeinasab M, Rad I, Bahonar A, Rashidi H, Fayaz A, Simani $\mathrm{S}$, et al. The prevalence of rabies and animal bites during 1994 to 2003 in Kerman province, southeast of Iran. Iran J Vet Res. 2007;8(4):343-50.

14. Sheikholeslami NZ, Rezaeian M, Salem Z. Epidemiology of animal bites in Rafsanjan, southeast of Islamic Republic of Iran, 2003-05. East Mediterr Health J. 2009;15(2):455-7. 
15. Vahdati SS, Mesbahi N, Anvarian M, Habibollahi P, Babapour S Demographics of rabies exposure in north-west of Iran: 5 years experience. J Anal Res Clin Med. 2013;1(1):18-21.

16. Majidpour A, Sadeghi-Bazargani H, Habibzadeh S. Injuries due to animal bites: a descriptive study. J Clin Res Gov. 2012;1(1):224.

17. Alavi SM, Alavi L. Epidemiology of animal bites and stings in Khuzestan, Iran, 1997-2006. J Infect Public Health. 2008;1(1):515 .

18. Bijari B, Sharifzade GR, Abbasi A, Salehi S. Epidemiological survey of animal bites in east of Iran. Arch Clin Infect Dis. 2011;6(2):90-2.

19. Eslamifar A, Ramezani A, Razzaghi-Abyaneh M, Fallahian V, Mashayekhi P, Hazrati M, et al. Animal bites in Tehran, Iran. Arch Iran Med. 2008;11(2):200-2.
20. Kassiri H, Kassiri A, Lotfi M, Shahkarami B, Hosseini S-S. Animal bite incidence in the County of Shush, Iran. J Acute Dis. 2014;3(1):26-30.

21. Kassiri H, Kassiri A, Pourpolad-Fard M, Lotfi M. The prevalence of animal bite during 2004-2008 in Islamabad-Gharb County, Kermanshah Province, Western Iran. Asian Pac J Trop Dis. 2014;4:S342-6.

22. Majidpour A, Arshi S, Sadeghi H, Shamshirgaran S, Habibzadeh S. Animal bites: epidemiological considerations in Ardabil Province, 2000. ARUMS. 2003;3(4):39-43.

23. Najafi N, Ghasemian R. Animal bites and rabies in northern Iran; 2001-2005. Arch Clin Infect Dis. 2009;4(4):224-7. 